Available online at www.sciencedirect.com

\section{ScienceDirect}

Materials Today: Proceedings 5 (2018) 10298-10305 materialstoday:
PROCELDINGS

www.materialstoday.com/proceedings

ECT 2016

\title{
Synthesis and Structure modification of Ionic Liquids to optimize their Thermoelectric Properties
}

\author{
Pilar Pérez ${ }^{\mathrm{a}}$, Stephanie Uhl ${ }^{\mathrm{b}}$, Edith Laux ${ }^{\mathrm{b}}$, Pauline Sanglard ${ }^{\mathrm{a}}$, Roger Marti ${ }^{\mathrm{a}}$, \\ Herbert Keppner ${ }^{\mathrm{b}}$ and Ennio Vanoli ${ }^{\mathrm{a} *}$ \\ a) HES-SO Haute école spécialisée de Suisse occidentale, Haute école d'ingénierie et d'architecture de Fribourg, Institute ChemTech, Bd de \\ Pérolles 80, CH-1700 Fribourg Switzerland

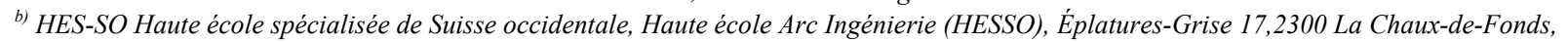 \\ Switzerland
}

\begin{abstract}
Ionic Liquids (IL) are organic salts with melting temperature typically below $100{ }^{\circ} \mathrm{C}$. The unique properties of ionic liquids such as their excellent chemical and thermal stabilities, their low vapor pressure, their important ionic conductivity makes them interesting compounds in material science and especially in thermoelectric generators (TEGs) for medical, pharma, or electronic applications. A big advantage of ILs is the endless number of cation/anion combinations, which allows synthesizing task-specific ionic liquids for TEG applications. This paper describes the synthesis, physical and electrochemical characterization of novel IL for application in thermoelectric generators (TEGs). We discuss the optimization of the chemical structure of IL regarding their thermoelectric properties via a structure-activity relationship approach. The best ionic liquids are the protic ones with a Seebeck coefficient of $570.24 \mu \mathrm{V} / \mathrm{K}$ for methylammonium trifluoroacetate and $-1424.56 \mu \mathrm{V} / \mathrm{K}$ for ethylammonium formate.
\end{abstract}

(C) 2017 Elsevier Ltd. All rights reserved.

Selection and/or Peer-review under responsibility of the Conference Committee Members of 14th EUROPEAN CONFERENCE ON THERMOELECTRICS.

Keywords: Ionic Liquid, Energy Harvesting, Thermoelectricity

* Corresponding author. Prof. Dr. E. Vanoli, phone+41 2642967 08, e-mail ennio.vanoli@hefr.ch

2214-7853 (C) 2017 Elsevier Ltd. All rights reserved.

Selection and/or Peer-review under responsibility of the Conference Committee Members of 14th EUROPEAN CONFERENCE ON THERMOELECTRICS. 


\section{Introduction}

ILs are organic salts with melting points generally bellow $100^{\circ} \mathrm{C}$. Their specific properties as good thermal stability or low vapor pressure are very convenient to use in thermoelectric generators (TEGs). Additionally, their physical and chemical properties can be optimize with different anion / cation combinations [1]. Two main classes of ILs can be highlighted: protic (PILs) and aprotic (AILs) ionic liquids. PILs can be advantageous compared to AILs in thermoelectric devices due to their available proton which is responsible for hydrogen bonding. PILs synthesis are realized by proton transfer while a neutralization reaction between a Brönsted base and acid [2]. The acid-base equilibrium and the temperature can change the properties of the IL [3]. Nevertheless, the proton transfer may be partial because of the different acid and based used. The ionic characteristics of PILs (i.g. degree of proton transfer polarity, iconicity) and related properties such as conductivity are, therefore, not easy to understand and quantify [4].

The Seebeck effect is the phenomena when an electric potential has been generated by a difference of temperature. The thermoelectric materials create these power directly from heat by converting temperature differences into electric voltage. High electrical conductivity and low thermal conductivity are the optimal properties for thermoelectric materials. The main three semiconductors known to have those are solids $\left(\mathrm{Bi}_{2} \mathrm{Te}_{3}, \mathrm{PbTe}\right.$ or $\left.\mathrm{SiGe}\right)$.

Seebeck coefficient (Se), power factor (PF) and thermoelectric figure of merit (ZT) are three important parameters used to evaluate the thermoelectric performance of potential thermoelectric materials[5]. As well-known from solid state devices, the figure of merit of a thermoelectric generator (TEG) is expressed in equation (1):

$$
Z=S e^{2} \frac{\sigma}{\lambda}
$$

To maximize the thermoelectric performance $(Z)$, lower thermal conductivity $(\lambda)$, higher electrical conductivity $(\sigma)$ and Seebeck coefficient $(\mathrm{Se}=\mathrm{dV} / \mathrm{dT})$ are required.

The unfavorable link between electrical and thermal conductivity limits the choice of solid-state materials for thermoelectric generators (TEG). An interesting alternative for solid-state TEG materials is the choice of ionic liquids that exhibits less thermal conductivity, and has the potential for being designed for delivering optimal thermoelectric properties [6].

The majority of the R\&D groups work with TEGs based on rigidity materials. Tritt et al. [7] work with bulk materials such as skutterudites, clatharates, half-Heusler alloys, and complex chalcogenides or Harman et al. [8] investigate PbSeTe-based quantum dot superlative structures. They work with thermoelectric materials in solid state to improve the Seebeck coefficient and decrease the thermal conductivity. The low thermal conductivity and high Seebeck coefficient of ionic liquids can resolve this problem. Initial studies with IL for TEG applications were done $[6,9]$ and showed promising results, this promoted us to evaluate in more detail IL regarding their thermoelectric properties via a structure-activity relationship approach. In addition, the use of ionic liquids allows the construction of flexible TEG applications [5].

The objective of the paper is to study new ionic liquids with a low viscosity, a high electric conductivity and Seebeck coefficient as well as the maximal power output. The special properties of those ionic liquids provide flexibility to the devices and make them interesting for medical, pharma, or electronic applications [2] as shown in Figure 1.
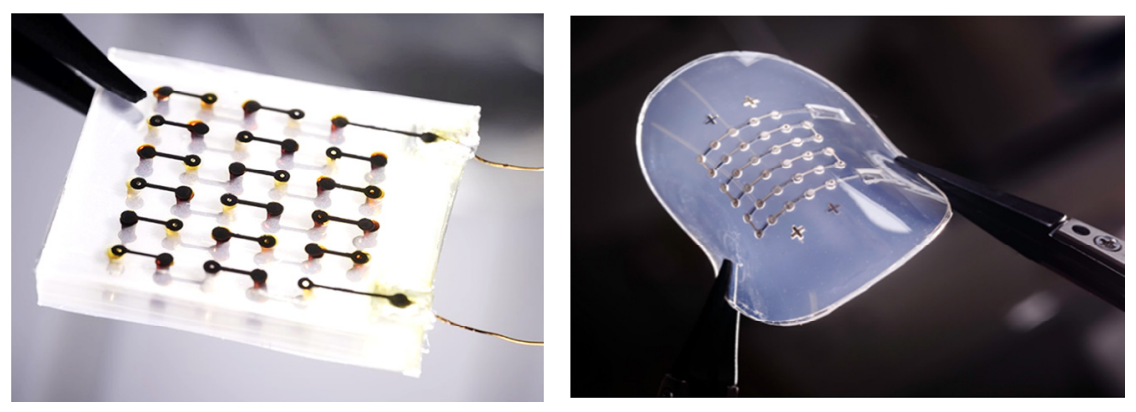

Figure 1. TEG flexible prototypes 


\section{Experimental}

\subsection{Materials}

All starting materials were supplied by Sigma-Aldrich and were used as received. Ionic liquids were purchased from IoLiTec or prepared in-house.

\subsection{Analysis}

NMR spectra were recorded at $300 \mathrm{MHz}$ (for ${ }^{1} \mathrm{H} \mathrm{NMR}$ ), $282 \mathrm{MHz}$ (for ${ }^{19} \mathrm{~F} \mathrm{NMR}$ ), or $75 \mathrm{MHz}$ (for ${ }^{13} \mathrm{C} \mathrm{NMR}$ ) in $\left(\mathrm{CD}_{3}\right)_{2} \mathrm{SO}$. Chemical shifts are reported as $\delta(\mathrm{ppm})$ downfield from tetramethylsilane $(\delta=0.00)$ using residual solvent signal as an internal standard.

Karl-Fisher water titration device (756 KF from Metrohm with Hydranal®-coulomat AD as titration solution) was used to determine that the water content was less than $1 \mathrm{wt} . \%$.

Kinematic viscosity measurements were performed using an Anton Paar MCR 300 rheometer at $25^{\circ} \mathrm{C}$.

Ionic conductivities were determined on a Metrohm 914 Conductometer with a frequency range of 50-60 Hz. The ionic conductivity was determined at $25^{\circ} \mathrm{C}$ for all ionic liquids.

A specifically test cell has been performed in order to characterization of the ionic liquids such as the currentvoltage characteristics of the generators. The IL container is sealed using a PDMS (Polydimethylsiloxane) ring that is squeezed (for tightness and contacting) between two metallized sapphire disks and clamped by two aluminum blocs. The aluminum parts are connected to a cooling circuit, respectively a heating system and on both sides the temperature can be monitored. Sapphire was used due to its good thermal conductivity; the Rhodium-metallized side is in contact to the liquid. The system is fully automatized allowing to measure the potential difference, current and the heating/cooling dynamics, as well as the stabilization of the measured data (Data Acquisition System Agilent 34970A, 34901A; thermocouple Typ K)[6].

\subsection{Synthesis of PILs}

PILs as shown in Table 1 are formed by proton transfer reaction between a Brönsted acid and a Brönsted base [10]. Typically, an equimolar amount of the acid was added dropwise to an ice-cold aqueous solution of the amine. The mixture was stirred at room temperature for several hours and then concentrated under vacuum to remove any water [11-13]. 
Table 1. Summary of NMR spectra results.

\begin{tabular}{|c|c|c|}
\hline Ionic Liquids & ${ }^{1} \mathrm{H}$ NMR (DMSO) & ${ }^{19}$ F NMR (DMSO) \\
\hline $\begin{array}{l}\text { Methylammonium } \\
\text { trifluoroacetate (META) }\end{array}$ & $\delta 2.09(\mathrm{~s}, 1 \mathrm{H})$ & $\delta-73.71(\mathrm{~s})$ \\
\hline $\begin{array}{l}\text { Ethylammonium } \\
\text { trifluoroacetate (EATA) }\end{array}$ & $\delta 7.88(\mathrm{~s}, 1 \mathrm{H}), 1.15(\mathrm{t}, \mathrm{J}=7.3 \mathrm{~Hz}, 1 \mathrm{H})$ & $\delta-73.71(\mathrm{~s})$ \\
\hline $\begin{array}{l}\text { Ethylammonium nitrate } \\
\qquad \text { (EAN) }\end{array}$ & $\delta 7.78(\mathrm{~s}, 1 \mathrm{H}), 2.85(\mathrm{q}, \mathrm{J}=7.3 \mathrm{~Hz}, 1 \mathrm{H}), 1.13(\mathrm{t}, \mathrm{J}=7.3 \mathrm{~Hz}, 1 \mathrm{H})$ & \\
\hline $\begin{array}{l}\text { Ethylammonium acetate } \\
\qquad \text { (EAA) }\end{array}$ & $\delta 7.49(\mathrm{~s}, 1 \mathrm{H}), 2.74(\mathrm{q}, \mathrm{J}=7.3 \mathrm{~Hz}, 1 \mathrm{H}), 1.73(\mathrm{~s}, 1 \mathrm{H}), 1.12(\mathrm{t}, \mathrm{J}=7.3 \mathrm{~Hz}, 1 \mathrm{H})$ & $\delta-73.71(\mathrm{~s})$ \\
\hline $\begin{array}{l}\text { Ethylammonium formate } \\
\qquad(\mathrm{EAF})\end{array}$ & $\delta 8.88(\mathrm{~s}, 1 \mathrm{H}), 8.40(\mathrm{~s}, 1 \mathrm{H}), 2.79(\mathrm{q}, \mathrm{J}=7.3 \mathrm{~Hz}, 1 \mathrm{H}), 1.12(\mathrm{t}, \mathrm{J}=7.3 \mathrm{~Hz}, 1 \mathrm{H})$ & \\
\hline $\begin{array}{l}\text { Ethylammonium } \\
\text { propionate (EAP) }\end{array}$ & $\begin{array}{l}\delta 8.70(\mathrm{~s}, 1 \mathrm{H}), 2.78(\mathrm{q}, \mathrm{J}=7.3 \mathrm{~Hz}, 1 \mathrm{H}), 2.02(\mathrm{q}, \mathrm{J}=7.6 \mathrm{~Hz}, 1 \mathrm{H}), 1.14(\mathrm{t}, \mathrm{J}=7.3 \mathrm{~Hz}, \\
1 \mathrm{H}), 0.94(\mathrm{t}, \mathrm{J}=7.6 \mathrm{~Hz}, 1 \mathrm{H}) .\end{array}$ & \\
\hline $\begin{array}{l}\text { Propylammonium nitrate } \\
\qquad \text { (PAN) }\end{array}$ & $\delta 2.85-2.65(\mathrm{~m}, 1 \mathrm{H}), 1.70-1.31(\mathrm{~m}, 1 \mathrm{H}), 0.89(\mathrm{t}, \mathrm{J}=7.5 \mathrm{~Hz}, 1 \mathrm{H})$ & \\
\hline $\begin{array}{l}\text { Diethylammnoium nitrate } \\
\text { (Et2NH2 NO3) }\end{array}$ & $\delta 3.08(\mathrm{q}, \mathrm{J}=7.3 \mathrm{~Hz}, 1 \mathrm{H}), 1.16(\mathrm{t}, \mathrm{J}=7.3 \mathrm{~Hz}, 1 \mathrm{H})$ & \\
\hline
\end{tabular}

\section{Results and discussion}

Keppner et al. [6] studied the generator properties in terms of free charge generation and separation and the change of polarity of the Seebeck coefficient. They concluded that ionic liquids with a high conductivity and a low viscosity appears promising. First, some ionic liquids from different kinds of cations and anions including inorganic and organic species were tested with the goal to identify the family of ionic liquids with the lowest viscosity and high electrical conductivity. In fact, ionic conductivity is directly affected by viscosity; the ionic conductivity decreases with the increase of viscosity [6]. The electrostatic attraction between the cations and anions, the tendency to form hydrogen bonds, the ion-ion interactions and van der Waals interactions have a big influence in the viscosity of ionic liquids [14].

The Table 2 resume the viscosity and ionic conductivity experimental measures for different ionic liquids. The Sebeeck coefficient and the power max measured with the demonstrator were resume in order to compare the performance of the different ionic liquids.

We conclude that the ammonium based ionic liquids had the best properties (high conductivity and lower viscosity) for TEGs applications. 
Table 2. Physical and thermoelectric properties (redox couple $\mathrm{LiI} / \mathrm{I}_{2} 0.2 \mathrm{M}$ at $25^{\circ} \mathrm{C}$ ) of different family of ionic liquids

\begin{tabular}{|c|c|c|c|c|c|c|}
\hline Ionic Liquid & Chemical Structure & $\begin{array}{c}\text { Viscosity } \\
{\left[\text { cPa·s, } 25^{\circ} \mathrm{C}\right]}\end{array}$ & $\begin{array}{l}\text { Conductivity } \\
{\left[\mathrm{mS} / \mathrm{cm}, 25^{\circ} \mathrm{C}\right]}\end{array}$ & $\begin{array}{c}\text { Seebeck Coefficient } \\
\text { Cool-down }[\mu V / K]\end{array}$ & $\begin{array}{c}\text { Power } \\
\text { max } \\
{[n W]}\end{array}$ & $\begin{array}{c}\Delta \mathbf{T} \\
{\left[{ }^{\circ} \mathbf{C}\right]}\end{array}$ \\
\hline EAN & & 2.76 & 17.81 & 677.34 & 4000 & 58 \\
\hline$[\mathrm{P} 666,14][\mathrm{Cl}]$ & & 71.24 & 5.92 & 226.33 & 10 & 52 \\
\hline [EMIM][EtSO4] & & 9.27 & 3.83 & 384 & 400 & 49 \\
\hline
\end{tabular}

Next we studied the effect of the alkyl chain in the cation and the structure of the anion in imidazolium ionic liquids on their viscosity and conductivity. As can be seen in Table 3 and Table 4, shorter alkyl chains in the cation are better and fluorinated anions have better results. This is in agreement with the finding by another authors $[2,14]$ that the electrical conductivity depends of the viscosity and the formula weight of the ionic liquid. The viscosity of ILs increases with the increment of alkyl chain length, this can be rationalized by the stronger van der Waals interactions. The interactions of the anion is much less well understood. Zhou et al. [14] propose that the anion design is important; fluorinated anions with low polarizability, high degrees of freedom, good charge distribution, and a somewhat flat shape are the best candidates. In addition, Siddique et al. [2] propose that ionic liquids containing fluorine atoms in the anions have a higher ionic conductivity as fluorine is more electronegative than hydrogen.

Table 3. Physical parameters of some examples of imidazolium ionic liquids

$\begin{array}{ll}\text { Ionic Liquids } & \begin{array}{c}\text { Viscosity } \\ {\left[\mathbf{c P a} \cdot \mathbf{s}, \mathbf{2 5}{ }^{\circ} \mathbf{C}\right]}\end{array}\end{array}$

Based on this findings, we synthesized different ammonium-based ILs with different lengths of alkyl chain and fluorinated anion to study their thermoelectric properties via a structure-activity relationship approach (see Table 5). The decrease of viscosity and high electric conductivity for these ionic liquids are in relation with their chain lengths and anions structure. The ammonium based cations with a longer alkyl chain like BAN (50.3 $\mathrm{cPa} \cdot \mathrm{s})$ has a higher viscosity than PAN $(3.84 \mathrm{cPa} \cdot \mathrm{s})$ or EAN $(2.8 \mathrm{cPa} \cdot \mathrm{s})$. 
Table 4. Physical parameters of some examples of ionic liquids with different anions.

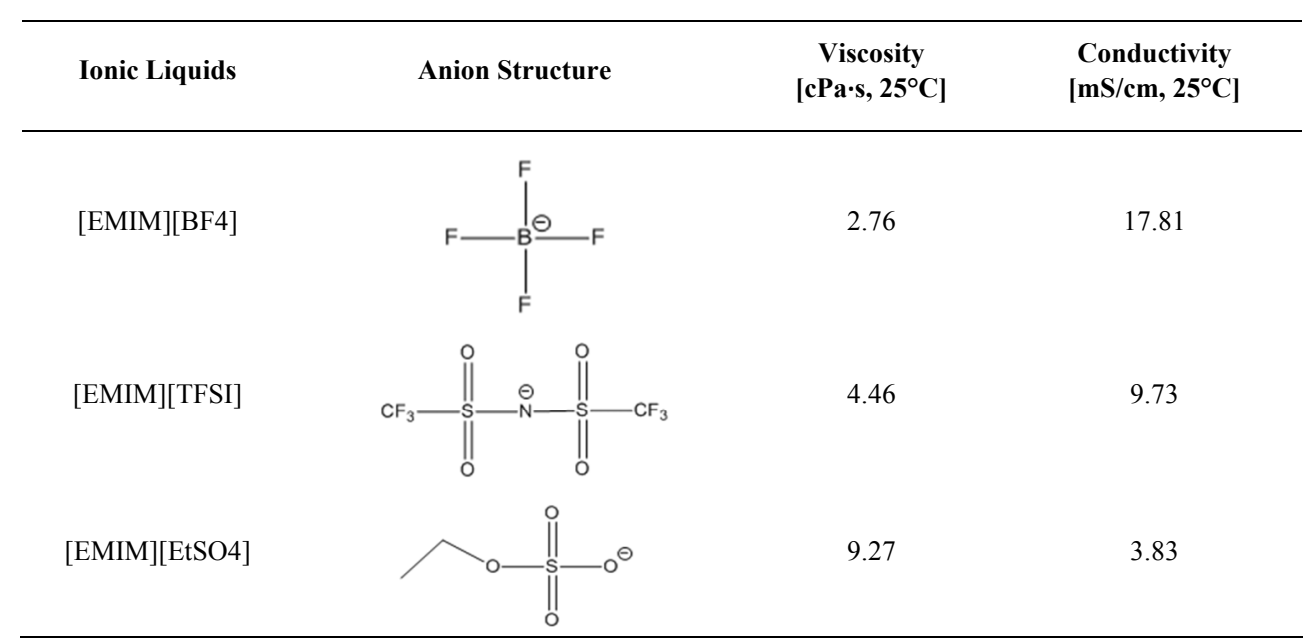

Table 5. Physical and thermoelectric parameters (Redox Couple $\mathrm{LiI} / \mathrm{I}_{2} 0.2 \mathrm{M}$ at $25^{\circ} \mathrm{C}$ ) of ammonium bases ionic liquids

\begin{tabular}{|c|c|c|c|c|c|c|}
\hline $\begin{array}{r}\text { Ionic } \\
\text { Liquid }\end{array}$ & Chemical Structure & $\begin{array}{c}\text { Viscosity } \\
{\left[\mathrm{cPa} \cdot \mathrm{s}, 2^{\circ} \mathrm{C}\right]}\end{array}$ & $\begin{array}{c}\text { Conductivity } \\
{\left[\mathrm{mS} / \mathrm{cm}, 25^{\circ} \mathrm{C}\right]}\end{array}$ & $\begin{array}{c}\text { Seebeck Coefficient } \\
\text { Cool-down }[\mu \mathrm{V} / \mathrm{K}]\end{array}$ & $\begin{array}{c}\text { Power max } \\
{[n W]}\end{array}$ & $\Delta \mathbf{T}\left[{ }^{\circ} \mathbf{C}\right]$ \\
\hline BAN & & 50.3 & 33.8 & 573.36 & 2300 & 62 \\
\hline PAN & & 3.84 & 18.2 & 503.67 & 2000 & 54 \\
\hline EAN & & 2.8 & 25.2 & 677.36 & 4000 & 58 \\
\hline EAF & & 20.7 & 16.3 & -1424.56 & 50 & 55 \\
\hline EAA & & 30.6 & 2.6 & 400.74 & 225 & 36 \\
\hline EAP & & 90.7 & 1.3 & 501.72 & 45 & 63 \\
\hline $\begin{array}{l}\mathrm{Et} 2 \mathrm{NH} 2 \\
\mathrm{NO} 3\end{array}$ & & a) & - & -325.83 & 350 & 57 \\
\hline EATA & & 11.97 & 46.1 & 584.64 & 2000 & 61 \\
\hline
\end{tabular}


MATA<smiles>C[NH2+]OC(=O)C(F)(F)F</smiles>

a) Solid at room temperature

On the other hand, in general the conductivity increase with shorter alkyl chains e.g. PAN $(18.2 \mathrm{mS} / \mathrm{m})<$ EAN $(25.2$ $\mathrm{mS} / \mathrm{m}$ ). The high conductivity for the sample of butylammonium nitrate (BAN) may be explained by his water contain. The presence of water in PILs can be greatly enhanced their conductivities properties, the decrease of their viscosity and increases the charge mobility and conductivity [4]. The Seebeck coefficients were all similar but the power of the demonstrator increase with fluorinated anions and low alkyl chains in the order EAA $(225 \mathrm{nW})<$ EAN $(4000 \mathrm{nW})<$ MATA $(5200 \mathrm{nW})$.

\section{Conclusion}

Ammonium based ionic liquids have demonstrated the best results toward thermoelectric applications. Maximal Seebeck coefficients and power output in TEG were measured as shown in Table 6. Compared to EAN our new ammonium based-ILs have similar Seebeck coefficients but they are more efficient regarding power output.

Table 6. Physical and thermoelectric parameters (Redox Couple $\mathrm{LiI} / \mathrm{I}_{2} 0.2 \mathrm{M}$ at $25^{\circ} \mathrm{C}$ ) of the best results ammonium bases ionic liquids.

\begin{tabular}{|c|c|c|c|c|c|}
\hline Species & $\begin{array}{c}\text { Viscosity } \\
{\left[\text { cPa.s, } 25^{\circ} \mathrm{C}\right]}\end{array}$ & $\begin{array}{c}\text { Conductivity } \\
{\left[\mathrm{mS} / \mathrm{cm}, 25^{\circ} \mathrm{C}\right]}\end{array}$ & $\begin{array}{c}\text { Seebeck Coefficient } \\
\text { Cool-down }[\mu \mathrm{V} / \mathrm{K}]\end{array}$ & $\begin{array}{c}\text { Power max } \\
{[n W]}\end{array}$ & $\begin{array}{c}\Delta \mathbf{T} \\
{\left[{ }^{\circ} \mathbf{C}\right]}\end{array}$ \\
\hline Methylammonium trifluoroacetate (META) & - & - & 570.24 & 5200 & 59 \\
\hline Ethylammonium nitrate (EAN) & 2.8 & 25.2 & 677.36 & 4000 & 58 \\
\hline Ethylammonium formate (EAF) & - & - & -1424.56 & 50 & 55 \\
\hline Buthylammonium nitrate (BAN) & 50.3 & 33.8 & 573.36 & 2300 & 62 \\
\hline
\end{tabular}

Although we obtained ionic liquids with large Seebeck coefficients, to employ them in TEG devices it requires to connect them in series in order to obtain the best high voltage $(\sim 1 \mathrm{~V})$. It is clear that to have additive contributions, ILs with positive and negative Seebeck coefficients are needed. Based on our optimization work, methylammonium trifluoroacetate (MET) with a positive Se of $570.24 \mu \mathrm{V} / \mathrm{K}$ and ethylammonium formate (EAF) with a negative Se of $-1451.9 \mu \mathrm{V} / \mathrm{K}$ are the best candidates for the construction of an TEG prototype.

ILs are easy to synthesize offer new possible applications. There are an extensive range of cation and anions combinations possible to prepare PILs with thermal and physicochemical interesting properties to employ them in TEGs. The fundamental properties of PILs will continue to be explored in order to optimize their thermoelectric characteristics. The results of these study has demonstrated their high potential at this field and be optimist to continue with the development of TEGs with ionic liquid integrate. The interest in PILs for use as electrolytes and incorporation in polymer electrolytes for energy storage devices is increased.

\section{Acknowledgements}

The project was funded by the HES-SO Interdisciplinary Project No. 011-2015-PI. 


\section{References:}

[1] Sanglard P, Vorlet O, Marti R, Naef O, Vanoli E. CHIMIA, 2013. 67: 711-718.

[2] Siddique TA, Balamurugan S, Said SM, Sairi NA, Normazlan WMDW. RSC Advances, 2016. 6: 18266-18278.

[3] Bodo E, Mangialardo S, Ramondo F, Ceccacci F, Postorino P. Journal of Physical Chemistry B, 2012. 116:

$13878-13888$.

[4] Greaves TL, Drummond CJ. Chemical Reviews, 2015. 115: 11379-11448.

[5] Jia HY, Tao XL, Wang YP. Advanced Electronic Materials, 2016. 2.

[6] Keppner H, Uhl S, Laux E, Jeandupeux L, Tschanz J, Journot T. Materials Today: Proceedings, 2015. 2: 680689.

[7] Tritt TM, Subramanian MA. Mrs Bulletin, 2006. 31: 188-194.

[8] Harman TC, Taylor PJ, Walsh MP, LaForge BE. Science, 2002. 297: 2229-2232.

[9] Abraham TJ, MacFarlane DR, Pringle JM. Energy \& Environmental Science, 2013. 6: 2639-2645.

[10] Belieres JP, Angell CA. Journal of Physical Chemistry B, 2007. 111: 4926-4937.

[11] Waichigo MM, Riechel TL, Danielson ND. Chromatographia, 2005. 61: 17-23.

[12] Greaves TL, Weerawardena A, Fong C, Krodkiewska I, Drummond CJ. Journal of Physical Chemistry B, 2006. 110: 22479-22487.

[13] Waichigo MM, Danielson ND. Journal of Chromatographic Science, 2006. 44: 607-614.

[14] Zhou ZB, Matsumoto H, Tatsumi K. Chemphyschem, 2005. 6: 1324-1332. 